\title{
Depolarizing Neuromuscular Blocking Action Induced by Electropharmacological Coupling in the Combined Effect of Paeoniflorin and Glycyrrhizin
}

\author{
Masayasu KIMURA, Ikuko KIMURA and Hiroshi NOJIMA \\ Department of Chemical Pharmacology, Faculty of Pharmaceutical Sciences. \\ Toyama Medical and Pharmaceutical University. Toyama 930-01. Japan
}

Accepted January 7, 1985

\begin{abstract}
Twitch tensions of indirectly stimulated diaphragm muscles of mice were blocked by a combination of paeoniflorin (PF) and glycyrrhizin (GLR). The mechanism of this effect was studied electropharmacologically. When twitch responses were completely prevented, miniature end-plate, end-plate, and muscle action potentials were still observed when PF and GLR were combined, suggesting that the mechanism is postsynaptic. Potential amplitudes induced by acetylcholine (ACh), which was injected iontophoretically, were inhibited by about $70 \%$ by PF $(25 \mu \mathrm{g} / \mathrm{ml})$ plus GLR $(75 \mu \mathrm{g} / \mathrm{ml})$, although neither agent alone caused an inhibition. The combined ratio ( $P F: G L R=1: 3)$ by concentrations $(\mathrm{g} / \mathrm{ml})$ potentiated both the inhibition of ACh potential amplitudes and the depolarization of resting membrane potentials. These results indicate that the effect of combined PF and GLR is to depolarize the muscle membrane and to block ACh-receptor-linked processes. In chemically skinned (saponin-treated) muscles, the tension induced by $0.39 \mu \mathrm{M}$ of free calcium was inhibited by PF $(300 \mu \mathrm{g} / \mathrm{ml})$, but it tended to be increased by GLR $(300 \mu \mathrm{g} / \mathrm{ml})$. Caffeine-induced contractures in the skinned muscles was not influenced by PF, and they tended to be decreased with GLR treatment. Thus, in muscles with sustained depolarization, these combined compounds seem to block intracellular $\mathrm{Ca}^{2+}$ movement.
\end{abstract}

In earlier papers (1, 2), we reported a new compound, paeoniflorigenone, which blocks neuromuscular junctions in skeletal muscle. This effect was greatly increased by glycyrrhizin (GLR) (3). Furthermore, the combination of paeoniflorin (PF) with GLR blocked indirectly stimulated twitching. PF or GLR alone at the concentrations used had no such effects. The mechanism involved was similar to that of succinylcholine (SuCh) in that 1) during complete blockage of indirectly stimulated twitching, the diaphragm muscle membrane may be depolarized and 2) a potentiation effect was observed when GLR was used in combination with SuCh. There was no such effect when d-tubocurarine (d-TC), instead of SuCh, was used in combination with GLR. Here, we investigate whether the effect of the combination of compounds is closely related to depolariza- tion and whether the site of action of the combined agents is presynaptic or postsynaptic. We use electropharmacology to study the mechanism of this phenomenon.

\section{Materials and Methods}

Experiments were carried out with isolated left diaphragm muscles from male ddY mice (body weight $30-40$ g, 8-12 weeks of age). The muscles were removed after the mice were decapitated and bled, pinned in a muscle bath, and perfused with Krebs-Henseleit solution ( $\mathrm{pH} \mathrm{7.2-7.4)} \mathrm{being}$ aerated with $95 \% \quad \mathrm{O}_{2}$ and $5 \% \quad \mathrm{CO}_{2}$. The solution contained $136.9 \mathrm{mM} \mathrm{NaCl}, 5.0 \mathrm{mM}$ $\mathrm{KCl}, 1.2 \mathrm{mM} \mathrm{MgSO}_{4}, 2.5 \mathrm{mM} \mathrm{CaCl}_{2}, 15.0 \mathrm{mM}$ $\mathrm{NaHCO}_{3}$ and $10 \mathrm{mM}$ glucose. The phrenic nerve was placed over platinum electrodes in an acrylic pool. The preparations were kept at $35-36^{\circ} \mathrm{C}$. 
Intracellular recording: Standard glass electrodes filled with $3 \mathrm{M} \mathrm{KCl}$ and with tip resistance of $20-40 \mathrm{M} \Omega$ were used for the intracellular recording of membrane potentials, which were measured using a microelectrode amplifier (Nihon Kohden Co. MEZ 8101). Only those cells having miniature end-plate potentials (m.e.p.p.) were used for this study. M.e.p.p. were recorded on a Visilight (San-ei, Model 5M21). Acetylcholine (ACh) chloride was applied iontophoretically near the muscle-cell surface through an electrode filled with $1 \mathrm{M} \mathrm{ACh}$, using a microiontophoresis unit (Diamedical, DPI-25) and a $V-1$ conversion unit (DPI-25 T).

Saponin treatment: Diaphragm muscle fibers, $0.5 \mathrm{~mm}$ wide, were treated for $30 \mathrm{~min}$ with $0.1 \mathrm{mg} / \mathrm{ml}$ saponin in the contracting solution containing $60 \mathrm{mM} \mathrm{K}_{2} \mathrm{SO}_{4}, 4 \mathrm{mM}$ $\mathrm{MgSO}_{4}, 20 \mathrm{mM}$ tris, $20 \mathrm{mM}$ maleic acid, $4 \mathrm{mM}$ ATP, and $2 \mathrm{mM}$ EGTA. Then they were washed out for $15 \mathrm{~min}$ and contracted by calcium ions in the contracting solution with or without the compounds listed below. The free $\mathrm{Ca}^{2+}$ concentration in a mixture of 300 $\mu \mathrm{M} \mathrm{CaCl}{ }_{2}$ added to the above solution was calculated to be $0.39 \mu \mathrm{M}$, using the dissociation constants of $2.3 \times 10^{-6} \mathrm{M}$ for $\left(\mathrm{Ca}^{2+}\right)(\mathrm{EGTA}) /(\mathrm{Ca}-\mathrm{EGTA})(4), 3.17 \times 10^{-5}$ $M$ for $\left(\mathrm{Ca}^{2+}\right)\left(\mathrm{ATP}^{4-}\right) /\left(\mathrm{CaATP}^{2-}\right)$, and $1.1 \times 10^{-5} \mathrm{M}$ for $\left(\mathrm{Mg}^{2+}\right)\left(\mathrm{ATP}^{4-}\right) /\left(\mathrm{MgATP}^{2-}\right)$ and assuming that $\left(\mathrm{ATP}^{-}\right)=1.59\left(\mathrm{ATP}^{-}{ }^{-}\right)$. After washing out the calcium solution with the contracting solution with or without the compounds below, contracture was immediately brought about using $20 \mathrm{mM}$ caffeine with or without those compounds added. These procedures were essentially those of Endo et al. (5)

Compounds: SuCh.2 $\mathrm{H}_{2} \mathrm{O}$ (Nakarai), ACh (Dai-ichi Seiyaku) and GLR monoammonium salt (a kind gift of Dr. S. Yabuki, the Minophagen Co.) were used. PF was generously provided, by Prof. O. Tanaka, Department of Pharmacognosy. Hiroshima University.

\section{Results}

Relationship between iontophoretic $\mathrm{ACh}$ pulses and $A C h$ potentials when $P F$ and GLR are combined: The amplitude of ACh potentials were measured with pulses of 0.1 .
$0.15,0.2,0.3$ and $0.4 \mathrm{nC}$ applied iontophoretically (Fig. 1). The histogram shows the numbers of $A C h$ potentials observed at each amplitude. Amplitudes in this logarithmic scale of ACh pulses were distributed normally. Normal distribution curves were shifted by a log pulse of $\mathrm{ACh}$ to the right, and did not by a pulse of $0.4 \mathrm{nC}$, indicating this is the submaximum pulse.

Since ACh potential amplitudes had a normal distribution, mean amplitudes were plotted against a logarithmic scale of the $\mathrm{ACh}$ pulse $(0.1,0.2,0.4,0.8,1.6$ and $3.2 \mathrm{nC})$ with $50 \mu \mathrm{g} / \mathrm{ml} P F, 150 \mu \mathrm{g} / \mathrm{ml}$ GLR, or $25 \mu \mathrm{g} / \mathrm{ml}$ PF with $75 \mu \mathrm{g} / \mathrm{ml}$ GLR (Fig. 2). Neither of the compounds alone at the concentration used blocked indirectly-stimulated twitching. but the combination of the agents blocked it completely (data not shown). ACh potentials with either compound alone did not differ from the control without it. The combination markedly suppressed these ACh potentials.

The $\mathrm{ACh}$ and the resting membrane potentials were plotted against the log of total concentrations $(\mathrm{g} / \mathrm{ml})$ of these substances, alone or in combination, in Fig. 3. The ratio PF:GLR was 1:3. ACh potentials were obtained using a constant maximum pulse of $3.2 \mathrm{nC}$. The results show that with these compounds together, the depolarizing and

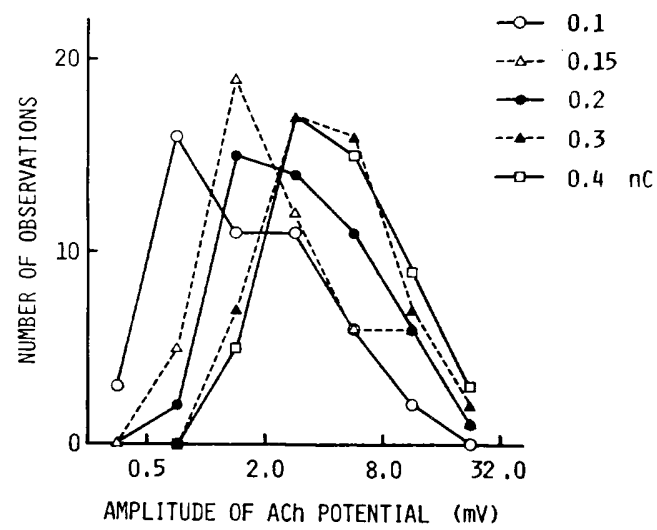

Fig. 1. Histogram of $\mathrm{ACh}$ potential amp!itudes (abscissa) of mouse diaphragm muscles. The ordinate shows the number of observations of potentials for each amplitude. ACh was ejected in pulses of $0.1(\bigcirc), 0.15(\Delta), 0.2(\mathbf{O}), 0.3(\mathbf{\Delta})$ and $0.4(\square) \mathrm{nC}(10 \mathrm{msec})$ iontophoretic application using a glass microelectrode filled with $1 \mathrm{M} \mathrm{ACh}$. 
postjunctional blocking action depended on concentration and that the blocking was much greater than for the compounds alone. so there was potentiation.

Effects on miniature end-plate and endplate potentials (e.p.p.): The effect of the combination of $150 \mu \mathrm{g} / \mathrm{ml} P F$ and $150 \mu \mathrm{g} / \mathrm{ml}$ GLR on m.e.p.p. was compared with that of SuCh $(10 \mu \mathrm{g} / \mathrm{ml}$, Fig. 4). Measurements were made either 1 or 20 min after starting the treatment with either SuCh or combined compounds. The combination did block

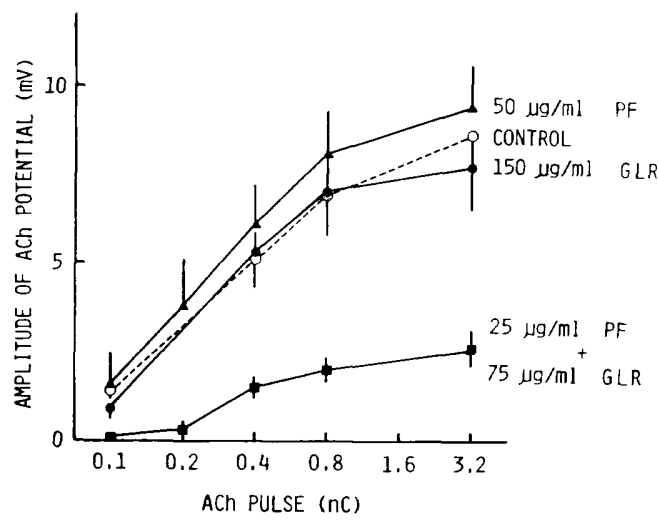

Fig. 2. Blocking by PF and GLR of ACh potentials in mouse diaphragm muscles. Mean amplitudes \pm S.E.M. $(n=13$ to 15$)$ of the potentials are plotted against $0.1,0.2,0.4,0.8$ and $3.2 \mathrm{nC}(10-64 \mathrm{msec}$ and 10-50 nA) with PF $(50 \mu \mathrm{g} / \mathrm{ml}, \boldsymbol{\Delta})$. GLR $(150$ $\mu \mathrm{g} / \mathrm{ml}$. ). PF $(25 \mu \mathrm{g} / \mathrm{ml})+\mathrm{GLR}(75 \mu \mathrm{g} / \mathrm{ml})$ (ם). and the control $(\bigcirc)$. indirectly-stimulated twitching, as we previously reported (3), but did not stop the m.e.p.p. However, SuCh completely suppressed m.e.p.p. In this respect the effect of the combination of PF and GLR is different from the effect of SuCh. The e.p.p. was recorded after $P F$ and GLR treatment for 20 min had completely suppressed indirectlystimulated twitchings (Fig. 5). In addition, this combination slightly decreased the

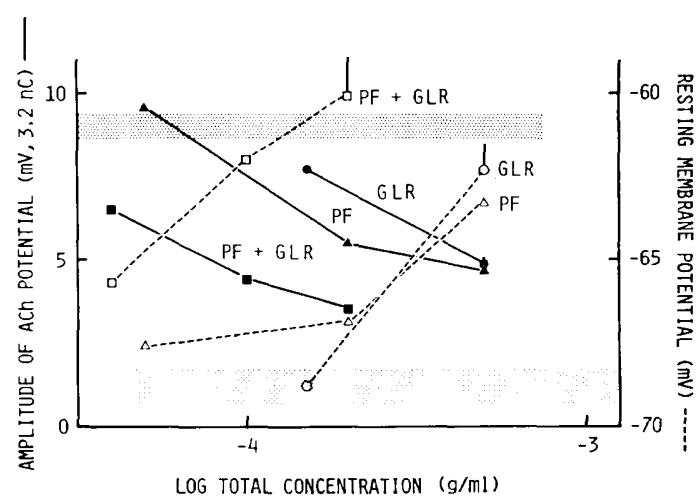

Fig. 3. The relationship between $\mathrm{ACh}$ potentials (solid line, closed symbol, $n=10$ to 34 ) and resting membrane potentials (dotted line, open symbols, $\mathrm{n}=8$ to 50$)$ plotted against $\log$ concentrations $(\mathrm{g} / \mathrm{ml})$ of PF alone (triangle), GLR alone (circle), and the combination of PF and GLR (1:3) (square). Shading indicates the mean amplitude of the ACh potentials (upper, $n=9$ to 15 ) and the mean membrane potential (lower, $n=11$ to 40 ), with \pm S.E.M.

$-72 \mathrm{mV}$ Control

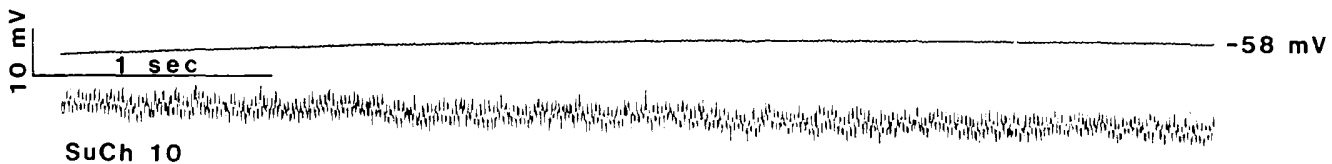

SuCh 10

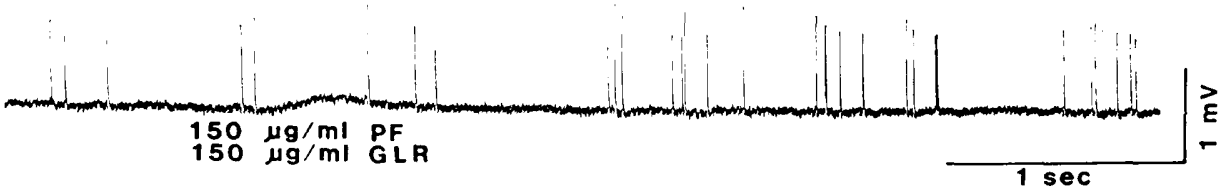

Fig. 4. M.e.p.p. $1 \mathrm{~min}$ after SuCh $(10 \mu \mathrm{g} / \mathrm{ml}$, middle trace) or $20 \mathrm{~min}$ after PF+GLR (both $150 \mu \mathrm{g} / \mathrm{ml}$, lower trace) treatment was started on isolated mouse diaphragm muscles. 


$$
\begin{aligned}
& 150 \mu \mathrm{g} / \mathrm{m} 1+\frac{P F}{}+{ }^{2} \\
& 150 \mu \mathrm{g} / \mathrm{ml} \\
& G L R
\end{aligned}
$$
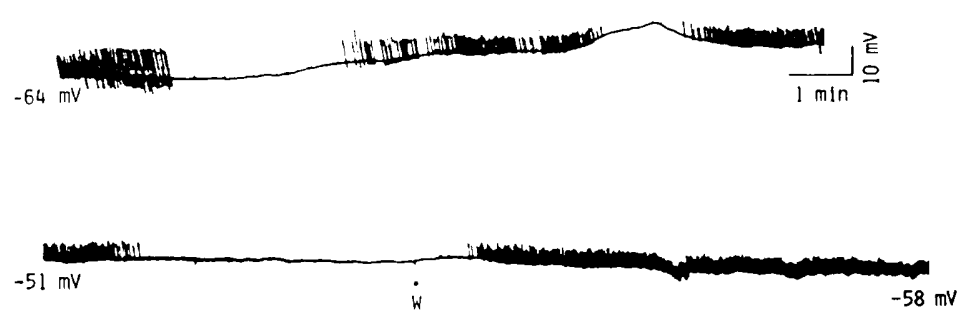

Fig. 5. Effect of PF with GIR (both $150 \mu \mathrm{g} / \mathrm{ml}$ ) on e.p.p. Mouse phrenic nerves were stimulated by $1 \mathrm{~Hz}$ pulses of supramaximal intensity, $1 \mathrm{msec}$ in duration. E.p.p. Was recorded after application of $20 \mathrm{~min}$ of $P F+G L R$ treatment, when indirectly-stimulated twitching was completely depressed. Control e.p.p. is the e.p.p. after washing out (W).

Table 1. Inhibition by PF or GLR of free $\mathrm{Ca}^{2+}$ or caffeine contraction in saponin-treated diaphragm muscle of mice

\begin{tabular}{lrcrl}
\hline & $\mathrm{n}$ & free $\mathrm{Ca}^{2+}(0.39 \mu \mathrm{M})$ & $\mathrm{n}$ & Caffeine $(20 \mathrm{mM})$ \\
Control & 26 & $18.1 \pm 2 . \%^{\mathrm{a}}$ & 26 & $16.4 \pm 1.9 \%$ \\
$\mathrm{PF}(300 \mu \mathrm{g} / \mathrm{ml})$ & 6 & $3.6 \pm 2.3^{*}$ & 6 & $13.1 \pm 3.1$ \\
$\mathrm{GLR}(300 \mu \mathrm{g} / \mathrm{ml})$ & 4 & $26.3 \pm 5.2^{\mathrm{b}}$ & 5 & $10.9 \pm 4.8^{\mathrm{b}}$ \\
\hline
\end{tabular}

${ }^{a}$ Contraction is shown as \% of the contraction by $152 \mathrm{mM} \mathrm{K}+$ in untreated muscle, \pm S. E.M. bNot significantly different from the control value $(P=0.05)$. $n$ : Numbers of observations. ${ }^{*}: P<0.05$.

frequency of e.p.p. These results showed that the combined compounds had little or no presynaptic action, which was therefore not part of the mechanism of the blocking action of the twitch response.

The direct effect of both compounds in activating muscles was examined by eliciting action potentials from a muscle fiber with a second electrode ( $5 \mathrm{msec}, 45 \mathrm{nA}$ ). Treatment with the combination of PF and GLR (both $150 \mu \mathrm{g} / \mathrm{ml}$ ) for $60 \mathrm{~min}$ did not affect the amplitude of the action potential during complete blocking of indirectly-stimulated twitching.

Effects on excitation-contraction coupling: The mechanism of the combined compounds were further studied using skinned muscle fibers. When $0.5 \mathrm{~mm}$ wide muscle fibers were treated with $0.1 \mathrm{mg} / \mathrm{ml}$ saponin, various drugs can permeate through the membrane and can then affect excitation-contraction coupling. The free $\mathrm{Ca}^{2+}(0.39 \mu \mathrm{M})$ contraction was decreased at $15 \mathrm{~min}$ after the application of PF $(300 \mu \mathrm{g} / \mathrm{ml})$, but the contraction caused by caffeine $(20 \mathrm{mM})$ was not (Table 1). GLR $(300 \mathrm{\mu g} / \mathrm{ml})$ tended to increase the contraction caused by free $\mathrm{Ca}^{2+}$, and it tended to reduce caffeine contracture.

\section{Discussion}

We previously (3) reported that GLR increased blocking by SuCh of indirectlystimulated twitching, but it did not change that of d-TC. Since SuCh is a depolarizing neuromuscular blocker, this effect of GLR may be closely linked to depolarizing effects in muscle membranes. GLR also potentiated inhibition of indirectly-stimulated twitching by paeoniflorigenone (2), a depolarizing blocker, and PF. Here, the combination of GLR and PF depolarized resting membrane potentials more than either compound alone. This combination also potentiated the inhibition of ACh potentials. GLR+PF also revealed the potentiation effect. Either compound alone induced the depolarization of resting membrane potentials and the inhibition of ACh potentials only at high concentrations. Whether the combination of GLR and paeoniflorigenone had such effects could not 
be studied, because the combination strongly depolarized resting membrane potentials.

The mechanism of the combined compounds was mainly postsynaptic, because m.e.p.p. and e.p.p. in the presence of the concentration of PF and GLR that caused neuromuscular blocking did not cease. Since amplitudes of muscle action potentials did not change during suppression of indirectlystimulated twitching, the combination does not act like tetrodotoxin.

In chemically skinned muscles, GLR tended to increase free $\mathrm{Ca}^{2+}$ contraction and to inhibit caffeine-induced contraction. These findings indicate that GLR does not inhibit contractile protein, and they suggest that $\mathrm{Ca}^{2+}$-induced $\mathrm{Ca}^{2+}$ release $(5,6)$ may be increased by GLR. Then GLR would tend to decrease caffeine contracture because of the resultant lesser load of $\mathrm{Ca}^{2+}$ in the sarcoplasmic reticulum. Since PF inhibited free $\mathrm{Ca}^{2+}$ contraction but did not affect caffeine contraction, it does not affect contractile protein or $\mathrm{Ca}^{2+}$ release from the sarcoplasmic reticulum.

The mechanism of the combined compounds is not that of dantrolene which inhibits contraction by reducing $\mathrm{Ca}^{2+}$ release from the sarcoplasmic reticulum (7), and weakly inhibits caffeine- and $\mathrm{Ca}^{2+}$-induced $\mathrm{Ca}^{2+}$ release $(8,9)$.

We conclude that the main effect of these combined compounds at the neuromuscular junction is to depolarize the muscle membrane long-term and to block some part of the processes in which ACh receptors work. That the effect of the combination was greater than that of the compounds alone is possibly related to electropharmacological coupling connecting GLR with PF. Thus, in muscles with sustained depolarization, the combined compounds seem to block intra- cellular $\mathrm{Ca}^{2+}$ movement.

\section{References}

1 Shimizu, M., Hayashi, T., Morita, N., Kimura, I., Kimura, M., Kiuchi, F., Noguchi, H., litaka, Y. and Sankawa, U.: Paeoniflorigenone, a new monoterpene from paeony roots. Tetrahedron Letters 22, 3069-3070 (1981)

2 Kimura, M., Kimura, I., Takahashi, K., Shimizu, M., Hayashi, T. and Morita, N.: Blocking effects of a new component, paeoniflorigenone in paeony root on neuromuscular junctions of frog and mouse. Japan. J. Pharmacol. 35, 61-66 (1984)

3 Kimura, M., Kimura, I., Takahashi, K., Muroi, M., Yoshizaki, M., Kanaoka, M. and Kitagawa, I.: Blocking effects of blended paeoniflorin or its related compounds with glycyrrhizin on neuromuscular junctions in frog and mouse. Japan. J. Pharmacol. 36, 275-282 (1984)

4 Ogawa, $Y$.: The apparent binding constant of glycolether-diaminetetraacetic acid for calcium at neural pH. J. Biochem. 64, 255-257 (1984)

5 Endo, M., Tanaka, M. and Ogawa, Y.: Calciuminduced release of calcium from the sarcoplasmic reticulum of skinned skeletal muscle fibers. Nature 228, 34-36 (1970)

6 Endo, M.: Conditions required for calciuminduced release of calcium from the sarcoplasmic reticulum. Proc. Japan Acad. 51, 467-478 (1975)

7 Endo, M. and Yagi, S.: Mechanism of action of dantrolene sodium, a peripherally acting muscle relaxant. In Kyoto Symposia, EEG Supp. No. 36. Edited by Buser, P.A., Cobb, W.A. and Okuma, T., p. 216-220, Elsevier Biomedical Press. Amsterdam (1982)

8 Ellis, K.O. and Bryant, S.H.: Excitation contraction uncoupling skeletal muscle by dantrolene sodium. Naunyn Schmiedebergs Arch. Exp. Pathol. Pharmakol. 274, 107-109 (1972)

9 Yagi, S. and Endo, M.: Effect of dantrolene on excitation-contraction coupling of skeletal muscle. Japan. J. Pharmacol. 26, Supp. 164P (1976) 